\title{
Silent by design? Tesla's Model S and the discourse on electric vehicle sound
}

\section{Stefan Krebs}

To cite this article: Stefan Krebs (2016): Silent by design? Tesla's Model S and the discourse on electric vehicle sound, Sound Studies, DOI: 10.1080/20551940.2016.1154406

To link to this article: http://dx.doi.org/10.1080/20551940.2016.1154406

曲 Published online: 15 Apr 2016.

Submit your article to this journal ¿

Q View related articles ¿

View Crossmark data ¿ 


\title{
Silent by design? Tesla's Model S and the discourse on electric vehicle sound
}

\author{
Tesla Motors Germany, Model S 85D (2015)
}

In November 2015, I found myself behind the wheel of one of the latest Tesla Model S vehicles: the 85D, an all electric car with $430 \mathrm{hp}$, four-wheel drive and an instant torque of $660 \mathrm{~N} \cdot \mathrm{m}$. It mixes the performance capacities of a powerful sports car with the size and appearance of a luxury sedan. My test drive started at the local Tesla branch in Düsseldorf but, before I could focus my attention on any car sounds, I had to learn to overlook the distracting 17-inch display in the centre console. Accompanied by one of Tesla's sales agents, my test drive took me on the nearby motorway, and then via country roads and small alleys back to our point of departure. Before writing this sound review, I closely listened to the sound recording I made during the test ride. This review then focuses on the interior soundscape of the Model $S$ and further looks at discussions about electric vehicle silence and the longstanding relation of (engine) power and noise.

Let me begin with a brief description of my initial auditory experience. While standing the Tesla S emits no sounds at all; the stopped motor is neither sounding nor vibrating. Putting the automatic transmission into Drive mode was signalled only by visual information with no accompanying functional sound - so before I accelerated, I did not hear a single technical audible indication. When I first tapped the accelerator, I heard only a faint hum. The sound can be described as a gentle whirr or whine; it comes from the two electric motors. When releasing the accelerator pedal a very similar tune is produced from the energy recovery systems. The sound level slightly depends on the intensity of the acceleration but always remains very low. Around 30 $\mathrm{mph}$, tyre noise starts to mask the soft motor sounds and, with growing speed, wind noise takes over and becomes rather prominent. At motorway speed, quite a lot of road and aerodynamic noise is audible.

The soft and rather high-pitched motor sound of the Model S contrasts with its amazing performance and questions culturally inscribed connotations of (engine) power and noise. Automotive historian Kevin Borg has recently described his experience of driving a Model $\mathrm{S}$ as a contradiction to "a lifetime of experiences and expectations about cars and sound. For a century, speed, power, and acceleration created unique (and loud) sound environments" (Borg 2014, 287). However, counterexamples exist in automotive history, too. During the interwar period a silent drive was perceived as the ultimate ride, even in a sports car. Maurice Goudard, president of the French Society of Automotive Engineers, nicely phrased this sonic desire for fast and silent cars in 1935: "Speed is the aristocracy of movement, yet silence is the aristocracy of speed". And his colleague H.-G. Laignier added in the same line of reasoning that yesterday's automobilists preferred noisy engines, which audibly reassured them to drive a powerful car, but today's car owners only "want to hear a faint whisper, like the rustling of silk" (Goudard and Laignier cited in Krebs 2011, 64 and 78). Automobile silence and luxury had long been associated (see Gartman 2004; Sheller 2004), and stressing both qualities was common in marketing campaigns and test reports of luxurious cars like Rolls-Royce; now, speed and power were also linked with silence. Yet, convincing prospective customers that a sports car also needed a silent engine required work: discursive work 
to decouple the symbolic links between speed, societal dominance and loud sound, on the one hand, and the building of new links between engine power and silence, on the other. This is exactly what French car manufacturers did during the 1920s and 30s. They used, for example, images like the panther to emphasise that silence, speed and power could go well together. A typical slogan for an open sports car read: "Fast and Silent, it overtakes! It's a Delage" (Krebs 2011,72). The notion of the powerful and silent engine was fuelled by findings in mechanical engineering that noise often indicated mechanical frictions and thus a loss of efficiency. Still, the silence of the interwar years was not silent in terms of decibels, as cars were more silent in marketing and engineering discourses than on real roads (Bijsterveld et al. 2014, 21-57). But the silent (sports) cars of the 1920 s and 30s are excellent examples that reveal the historical contingency of contemporary associations between automobile power and loud sound.

That these older links between silence and powerful engines seem long forgotten are indicated in discussions amongst Tesla owners and enthusiasts on web fora like MyTesla or TeslaMotorsClub. One discursive strand is of particular interest here: it centres around Tesla's interior noise level. While all discussants agree that the electric motors are barely audible, some complain about the high level of road and wind noise.' Often comparisons with other car models are drawn, in most cases the interior silence of luxurious sedans is stressed to emphasise the lack of comfortable silence in the Model S. The whole discussion basically revolves around the question whether the Model $\mathrm{S}$ is supposed to be a performance or a luxury car. In the former case, noise would not be an issue because today's sports cars don't have to be silent; in the latter case, interior silence would be one of the essential qualities. In defence of Model $S$ as a luxury sedan some owners even use smartphone apps to measure the actual sound level under different driving conditions and compare their figures with measurements from other car models. Yet, measuring results differ a lot: some show Model S acoustically on par with comparable luxury cars; others show excessive sound levels as high as $80 \mathrm{~dB}$. In addition to measurements, some discussants mention their observation that the absence of any motor noise and vibration raises the sonic awareness for other sounds like tyre and wind noise. This phenomenon was also encountered by French engineers in the interwar period; in their quest for the silent car they had to learn that quieting one source of noise often made other unwanted sounds come to the foreground (Krebs 2011, 73).

Despite the above mentioned persistence of links between powerful engines and loud sounds, electric vehicles with silent motors could also help to break with these older conventions. This is highlighted by discussions about the desirability of artificial engine sounds for electric vehicles. While some enthusiasts embrace the idea of hearing the sounds of well known sports car engines when speeding in their Tesla, most owners stress the beauty of a silent drive. User "rbergquist" puts it straight: "Noise from a car is so yesterday". Still, most discussants agree that it will take a long time to alter automobilists' sonic attitudes. ${ }^{2}$ It is interesting to note that Tesla does very little to promote the vision of a silent automobile future. On Tesla's website, for example, noise engineering of their Model $S$ is only mentioned to point out the studio quality of the audio entertainment system but not to highlight interior sound quality. This absence can be explained by looking at the way Tesla tries to construct the self-image of being distinctive. In advertisements, Tesla often stresses the radical divergence of fully electric vehicles from the old world of gasoline-powered automobiles. This emphasis on being different is best visible in the commercial "Modern Spaceship" in which a little boy imagines he could fly into space in his dad's Model S (Tesla 2014). Being unique seems to make any references to old or contemporary automobile values inappropriate: be it the whisper-silent drive of the interwar years or the roar of contemporary gasoline sports cars. However, rhetorically bypassing the interior silence of the Model S makes it look more like the byproduct of electric technology than a deliberate design choice. 


\section{Notes}

1. "too much sound!" and "Road noise" www.mytesla.com (December 2013 and March 2014); "is model S quieter than Lexus" www.teslamotorsclub.com (November 2012).

2. "Possible future software update: Simulated engine sound" and "Fake engine noise in ICE vehicles" MyTesla.com (July 2013 and January 2015).

\section{Notes on contributor}

Stefan Krebs is Senior Researcher at the Institute for History at the University of Luxembourg. In his current research project he investigates the history of 3D audio recordings. In 2014 he received the ICOHTEC Maurice Daumas prize for his article "Dial Gauge versus Senses 1 - 0: German Auto Mechanics and the Introduction of New Diagnostic Equipment, 1950-1980".

\section{References}

Bijsterveld, Karin, Eefje Cleophas, Stefan Krebs, and Gijs Mom. 2014. Sound and Safe: A History of Listening Behind the Wheel. New York: Oxford University Press.

Borg, Kevin. 2014. "Introduction: Constructing Sociotechnical Environments - Aurality, Air Quality, and Automobiles." Technology and Culture 55, (2): 287-298.

Gartman, David. 2004. "Three Ages of the Automobile: The Cultural Logics of the Car." Theory, Culture \& Society 21, (4-5): 169-195.

Krebs, Stefan. 2011. "The French Quest for the Silent Car Body: Technology, Comfort, and Distinction in the Interwar Period." Transfers 1 (3): 64-89.

Sheller, Mimi. 2004. "Automotive Emotions. Feeling the Car." Theory, Culture \& Society 21 (4-5): 221-242.

Tesla. 2014. "Modern Spaceship." Commercial. www.youtube.com/watch?v=KKbRAazkiWc

Stefan Krebs

Institute for History, University of Luxembourg @stefan.krebs@uni.lu

(C) 2016 Stefan Krebs http://dx.doi.org/10.1080/20551940.2016.1154406 